\title{
Mach 4 Test Results of a Dual-Flowpath, Turbine Based Combined Cycle Inlet
}

\author{
Cindy W. Albertson, ${ }^{1}$ Saied Emami, ${ }^{2}$ and Carl A. Trexler ${ }^{3}$ \\ NASA Langley Research Center \\ Hampton, Virginia 23681-2199
}

\begin{abstract}
An experimental study was conducted to evaluate the performance of a turbine based combined cycle (TBCC) inlet concept, consisting of a low speed turbojet inlet and high speed dual-mode scramjet inlet. The main objectives of the study were (1) to identify any interactions between the low and the high speed inlets during the mode transition phase in which both inlets are operating simultaneously and (2) to determine the effect of the low speed inlet operation on the performance of the high speed inlet. Tests were conducted at a nominal freestream Mach number of 4 using an 8 percent scale model representing a single module of a TBCC inlet. A flat plate was installed upstream of the model to produce a turbulent boundary layer which simulated the full-scale vehicle forebody boundary layer. A flowmeter/back pressure device, with remote actuation, was attached aft of the high speed inlet isolator to simulate the back pressure resulting from dual-mode scramjet combustion. Results indicate that the inlets did not interact with each other sufficiently to affect inlet operability. Flow spillage resulting from a high speed inlet unstart did not propagate far enough upstream to affect the low speed inlet. Also, a low speed inlet unstart did not cause the high speed inlet to unstart. The low speed inlet improved the performance of the high speed inlet at certain conditions by diverting a portion of the boundary layer generated on the forebody plate.
\end{abstract}

\section{Nomenclature}

$B L \quad$ boundary layer

$B P \quad$ back pressure

CRI geometric internal contraction ratio

ESP electronic scanning pressure

$H \quad$ height

HSC high speed cowl

HSI high speed inlet

LSC low speed cowl

LSI low speed inlet

$M \quad$ Mach number

M4BDF Mach 4 Blow Down Facility

NASP National Aero-Space Plane

$p \quad$ pressure

$q \quad$ dynamic pressure

Re Reynolds number

$T \quad$ temperature

TBCC turbine-based combined cycle

$\delta^{*} \quad$ boundary-layer displacement thickness

$\theta \quad$ cowl angle

\footnotetext{
${ }^{1}$ Senior Research Engineer, Vehicle Analysis Branch.

${ }^{2}$ Senior Research Engineer, Hypersonic Airbreathing Propulsion Branch.

${ }^{3}$ Senior Research Engineer, Retired.
} 


\begin{tabular}{ll}
\multicolumn{2}{l}{ Subscripts } \\
aw & adiabatic wall \\
e & boundary-layer edge \\
FM & flowmeter \\
le & leading edge \\
max & maximum \\
o & stagnation \\
th & inlet throat \\
w & wall \\
1 & freestream
\end{tabular}

\section{Introduction}

$\mathrm{T}$

$\neg$ HE Turbine Based Combined Cycle (TBCC) engine ${ }^{1-3}$ is a multi-flowpath concept that utilizes turbojet propulsion from take-off to approximately Mach 4, which is then replaced by the ram/scram propulsion system for increased velocities. This concept is applicable to hypersonic air-breathing cruise vehicles. As shown schematically in Fig. 1, the concept consists of low and high speed flowpaths, with the low speed flowpath incorporating the turbojet and the high speed flowpath incorporating the dual-mode scramjet.

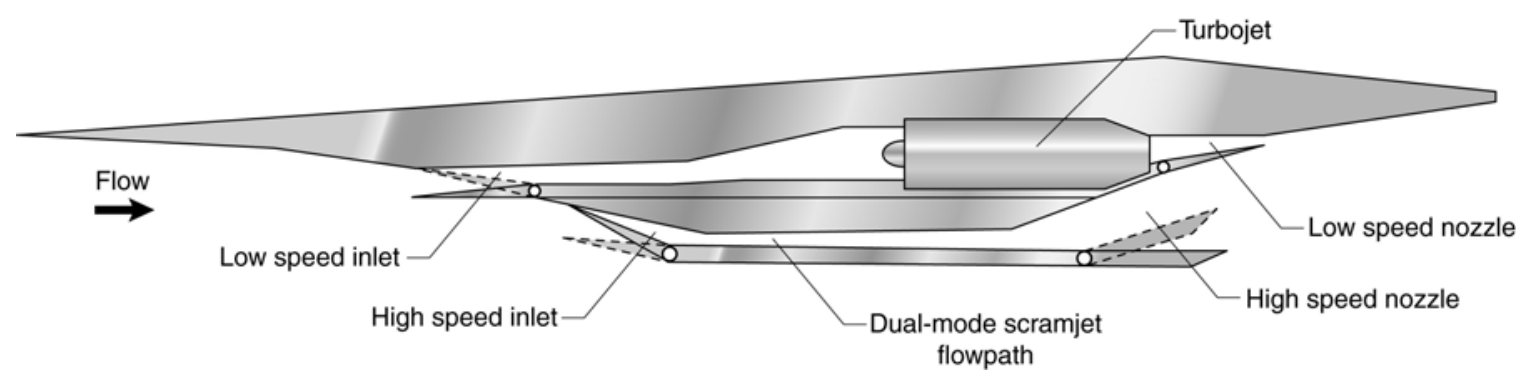

Figure 1. Turbine Based Combined Cycle (TBCC) engine integration.

One of the concerns with TBCC configurations is the potential of the two flowpaths to interfere with each other during the mode transition phase in which both the low-speed turbojet inlet and the high-speed dual-mode scramjet inlet are operating simultaneously. In fact, there is little information available in the literature that relates the combined operation of the high speed inlet to the low speed inlet. Inlet operability and performance are strongly dependent on specific inlet geometries. Also, a clear definition of the effects of the vehicle boundary layer on the low speed inlet and thus the high speed inlet is crucial. Therefore, the primary objectives of the present experimental study are (1) to identify any interactions between the high and low speed inlets, and (2) determine any high speed inlet performance enhancements or penalties resulting from low speed inlet operation. Secondary objectives are to determine the contraction ratio capabilities of both inlets, the back pressure capability of the high speed inlet, the high-speed inlet mass capture, and to support CFD analysis.

\section{Description of Experiment}

\section{A. Model and Instrumentation}

The model (Fig. 2) was an 8-percent scale, two-dimensional TBCC inlet module. Both the high and low speed inlets incorporated variable geometry cowl flaps that could be remotely actuated during testing. The forebody ramp located upstream of the low-speed inlet (LSI) was fenced to eliminate flow spillage. A $7.0 \mathrm{in} .(17.8 \mathrm{~cm})$ long boundary-layer plate was installed upstream of the ramp to simulate vehicle forebody boundary-layer effects on inlet performance. This plate spanned the 9 in. $(22.9 \mathrm{~cm})$ width of the M4BDF.

A flowmeter/back pressure device, with remote actuation, was attached aft of the high speed inlet (HSI) isolator, to simulate combustion-induced back pressure (Fig. 2). This device was instrumented to allow the captured mass flow through the HSI to be determined. The overall length of the inlet model and flowmeter was 35.6 in. (90.4 $\mathrm{cm})$. The LSI was not back pressured during the tests discussed in this report.

The model instrumentation consisted of 75 static pressure taps, three high frequency pressure transducers, and two thermocouples. The locations of the instrumentation are shown schematically in Fig. 3. Most of the 
instrumentation was located within the HSI because it was the main focus of the study. A photograph of the model installed in the test section of the M4BDF is shown in Fig. 4. The fence and sidewall were removed to show the low and high speed inlet flowpaths.

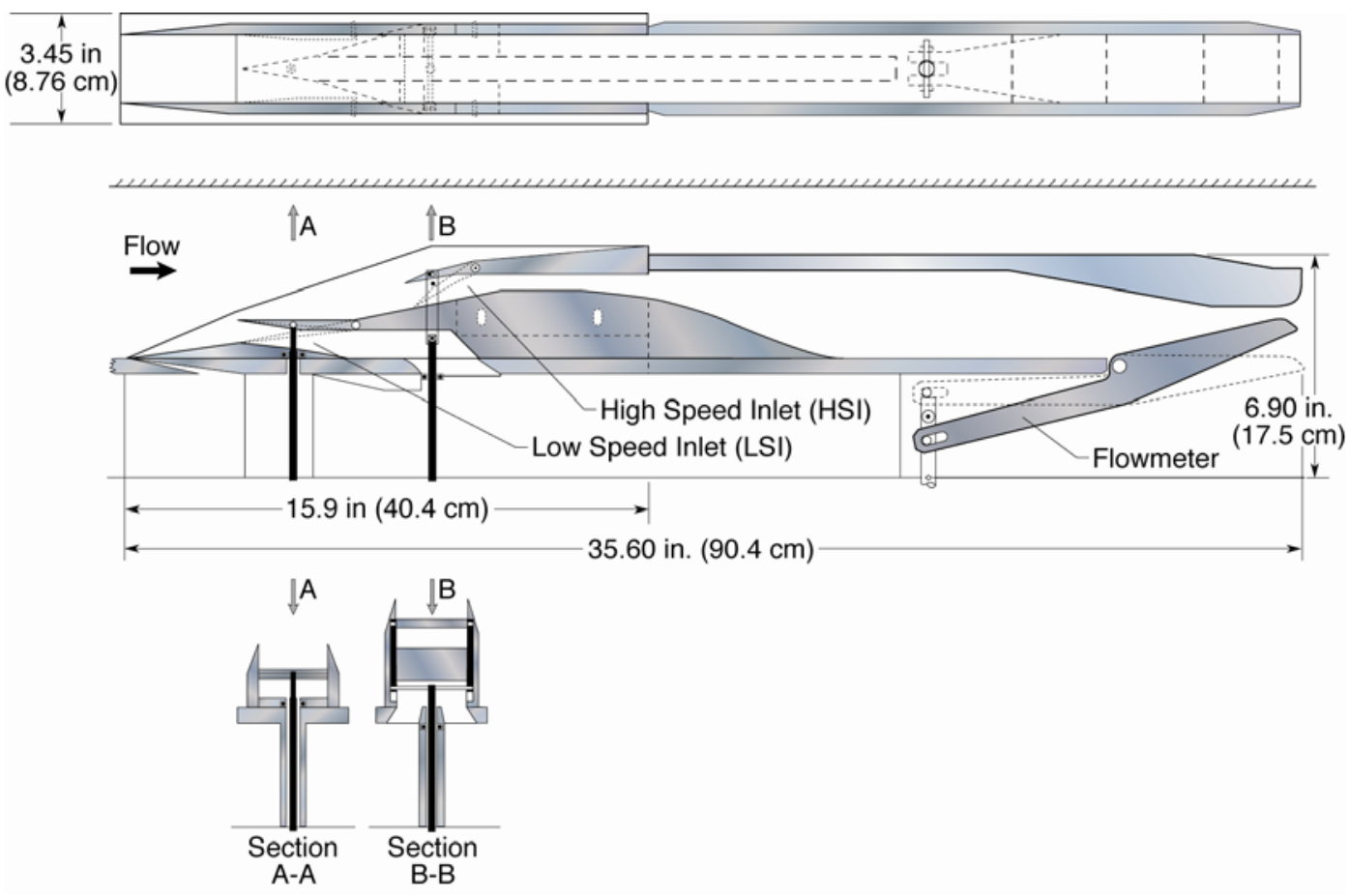

Figure 2. Schematic of TBCC inlet model with flowmeter.

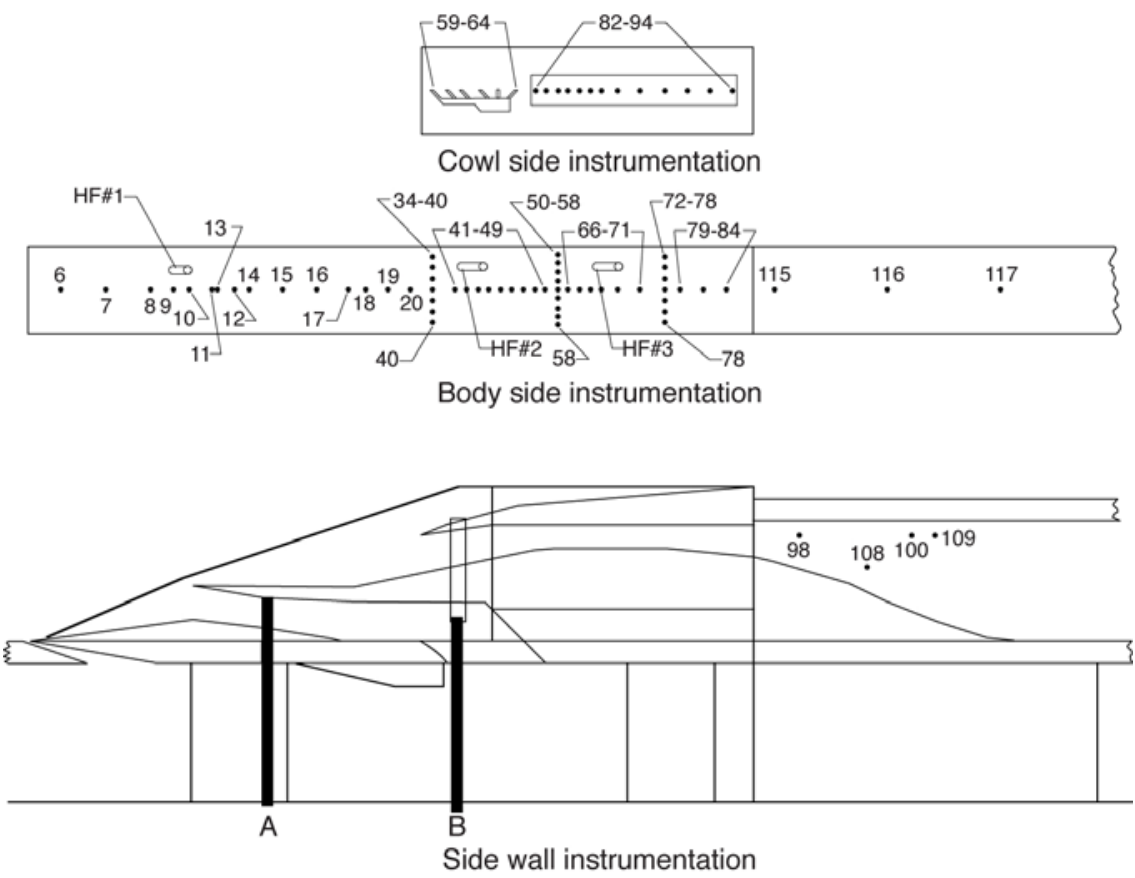

Figure 3. Model instrumentation.

American Institute of Aeronautics and Astronautics 


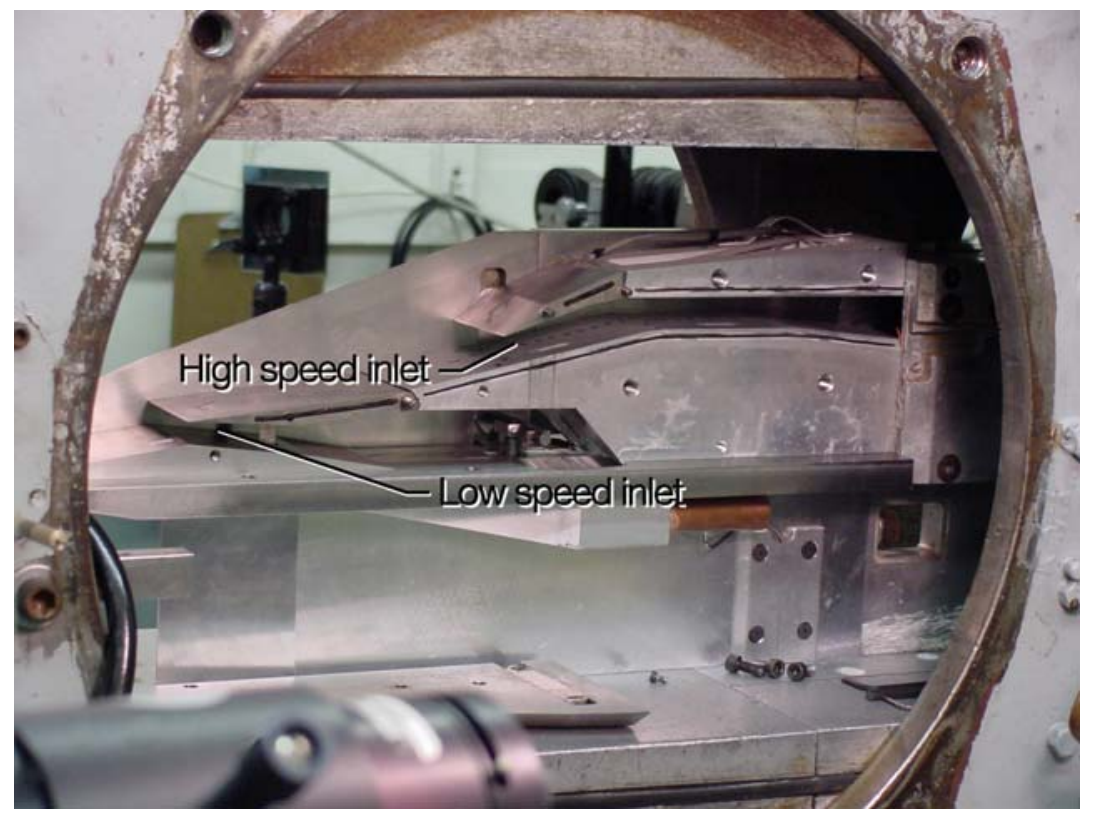

Figure 4. Model installed in the NASA Langley Mach 4 Blow Down Facility (fence and sidewall removed).

\section{B. Test Facility and Data Acquisition}

The model was tested in the NASA Langley Mach 4 Blow Down Facility (M4BDF). ${ }^{5}$ The M4BDF has historically been used as a screening facility for various subscale inlet designs, including inlets developed under NASA-led hypersonics programs ${ }^{4}$ (e.g.: NASP, Hyper-X, X-43B, X-43C), inlets designed by industry and academia (Pratt \& Whitney, Rocketdyne, Hampton University), and inlets designed under generic, in-house programs (e.g.: streamlined-traced inlet, reverse sweep sidewall compression inlet, translating strut inlet, etc.). The M4BDF is a relatively simple, inexpensive, quick-turnaround test facility that uses ambient-temperature air (nominally $520{ }^{\circ} \mathrm{R}$ or $289 \mathrm{~K}$ ) expanded through a two-dimensional, fixed-geometry nozzle to Mach 4.03 upstream of the inlet. The exit dimensions of the facility nozzle are 9.0 by 9.0 inches $(22.9$ by $22.9 \mathrm{~cm})$ and the length of the test section is approximately 15 inches $(38.1 \mathrm{~cm})$. Quartz windows are installed in the walls of the test section to provide visual access for Schlieren and other nonintrusive techniques. The facility is typically operated at stagnation pressures ranging from 150 to $250 \mathrm{psia}$ (1.03 to $1.72 \mathrm{MPa}$ ), corresponding to freestream static pressures ranging from 0.950 to 1.58 psia (6.55 to $10.9 \mathrm{kPa}$ ) and freestream unit Reynolds numbers ranging from $15.75 \times 10^{6} \mathrm{ft}^{-1}$ to $26.25 \times 10^{6} \mathrm{ft}^{-1}$ $\left(51.73 \times 10^{6} \mathrm{~m}^{-1}\right.$ to $\left.86.12 \times 10^{6} \mathrm{~m}^{-1}\right)$. The freestream static temperature is nominally $122{ }^{\circ} \mathrm{R}(68 \mathrm{~K})$.

Model static pressure data were acquired using a Pressure Systems Inc. Model 780B Electronically Scanning Pressure (ESP) system controlled using commercially available software (Labview $\left.{ }^{\circledR}\right)^{6}$ running on a Pentium ${ }^{\circledR}$ processor. Other model data included HSI wall temperature measurements from thermocouples and potentiometer outputs corresponding to the positions of the high and low speed cowl flaps and flowmeter/back pressure device flap. These data were all acquired at $1 \mathrm{~Hz}$. A separate high frequency DAS system was used to record the outputs of the high frequency pressure transducers at $10 \mathrm{kHz}$. The high frequency data will be discussed in a separate report.

\section{Test Conditions and Procedure}

The tests were conducted at a stagnation temperature and pressure of approximately $520{ }^{\circ} \mathrm{R}(289 \mathrm{~K})$ and 200 psia (1.38MPa), respectively, and a nominal freestream Mach number of 4.03. The model was positioned at 0 degrees angle of attack. The flight conditions duplicated a freestream Mach number of 4.03, freestream dynamic pressure of $1000 \mathrm{psf}(47.9 \mathrm{kPa})$, and vehicle angle of attack of 0 degrees. The local Reynolds number based on LSI cowl height (full open) was $1.37 \times 10^{6}$ for the inlet tests, compared to $1.49 \times 10^{6}$ for flight. Most of the tests were conducted with the 7.0 in. $(17.8 \mathrm{~cm})$ long boundary layer plate installed upstream of the model. This plate produced a turbulent boundary layer which nearly matched the scaled flight boundary layer displacement thickness at the low speed cowl (LSC) entrance plane (Table 1). The boundary layer displacement thicknesses shown in the table were 
computed using a flat plate boundary layer computer program ${ }^{7}$ and transition criteria developed during the NASP program. $^{8}$

\begin{tabular}{|c|c|c|c|c|c|}
\hline \multicolumn{6}{|c|}{ Tunnel and Model Conditions } \\
\hline $\mathbf{M}_{1}$ & $\mathbf{T}_{01}$ & $\mathbf{P}_{\mathbf{0}}$ & $\mathbf{R e}_{\text {LSC }}$ & $\begin{array}{c}\delta^{*} / \mathrm{H}_{\mathrm{LSC}} \\
\text { (BL plate) }\end{array}$ & $\begin{array}{c}\delta^{*} I \mathbf{H}_{\text {LSC }} \\
\text { (no plate) }\end{array}$ \\
\hline \multirow[t]{2}{*}{4.03} & $520 \mathrm{R}$ & 200 psia & $1.37 \times 10^{6}$ & 5.0 & 1.4 \\
\hline & $(289 \mathrm{~K})$ & (1.38MPa) & & & \\
\hline \multicolumn{6}{|c|}{ Flight Parameters } \\
\hline $\mathbf{M}_{1}$ & $T_{01}$ & $\mathbf{q}_{1}$ & $\mathbf{R e}_{\text {LSC }}$ & $\delta^{*} / \mathbf{H}_{\mathrm{LSC}}$ & \\
\hline \multirow[t]{2}{*}{4.03} & $520 \mathrm{R}$ & $1000 \mathrm{psf}$ & $1.49 \times 10^{6}$ & 5.4 & \\
\hline & $(289 \mathrm{~K})$ & $(47.9 \mathrm{kPa})$ & & & \\
\hline
\end{tabular}

Table 1. Test conditions compared to flight.

Initially, the wall temperature of the inlet model was at ambient temperature (approximately $530{ }^{\circ} \mathrm{R}$ or $294 \mathrm{~K}$ ), resulting in a moderately warm wall condition with a wall-to-adiabatic wall temperature ratio $\left(\mathrm{T}_{\mathrm{w}} / \mathrm{T}_{\mathrm{aw}}\right)$ of approximately 1.10. The model wall temperature would decrease during the two minute run to an average temperature of approximately $510{ }^{\circ} \mathrm{R}(284 \mathrm{~K})$, resulting in a slight decrease in $\mathrm{T}_{\mathrm{w}} / \mathrm{T}_{\mathrm{aw}}$ to approximately 1.06 .

A total of 91 runs were conducted with the TBCC inlet model to assess the influence of the LSI on the HSI performance, the inlet operability of both the HSI and the LSI, and the backpressure performance of the HSI. Variables included the HSI throat height ( $\mathrm{H}_{\mathrm{HSI}}$, th $)$, HSI and LSI cowl angles ( $\theta_{\mathrm{HSC}}$ and $\theta_{\text {LSC }}$, respectively), and the throat height of the flowmeter/back pressure device. The HSI throat height was set prior to testing and ranged from $60 \%$ to $100 \%$ of the scaled design height. The HSI and LSI cowl angles could be varied during testing using mechanical actuators. The throat height of the flowmeter/back pressure device for the HSI could also be varied during testing using a mechanical actuator. Typically only one of the devices would be actuated at a time during a run, as illustrated in Table 2.

\begin{tabular}{|c|c|c|c|c|}
\hline $\mathbf{H}_{\text {HSI, th }} / \mathbf{H}_{\text {Design }}$ & $\begin{array}{c}\text { BL plate } \\
\text { installed? }\end{array}$ & $\boldsymbol{\theta}_{\text {LSC }}$ & $\boldsymbol{\theta}_{\text {HSC }}$ & BP HSI? \\
\hline & & & & \\
\hline 0.60 & no & fixed & varied & no \\
\hline 0.60 & no & varied & fixed & no \\
\hline 0.60 & yes & fixed & varied & no \\
\hline 0.60 & yes & varied & fixed & no \\
\hline 0.60 & yes & fixed & fixed & yes \\
\hline 0.80 & yes & fixed & varied & no \\
\hline 0.80 & yes & varied & fixed & no \\
\hline 0.80 & yes & fixed & fixed & yes \\
\hline 1.00 & yes & fixed & varied & no \\
\hline 1.00 & yes & varied & fixed & no \\
\hline 1.00 & yes & fixed & fixed & yes \\
\hline
\end{tabular}

Table 2. Summary of model test parameters.

A test sequence corresponding to a HSI contraction ratio unstart is shown in Fig. 5. This type of test is typically done to determine inlet operability limits with only minimum backpressure (i.e.: the throat of the backpressure device is set to just above the choked flow limit. The HSI cowl angle, $\theta_{\mathrm{HSC}}$, shown by the pink line, was slowly increased, resulting in a slowly increasing contraction ratio. The LSI cowl angle was kept constant, as was the 
flowmeter flap height. At some point, the pressure just upstream of HSI cowl, p $_{\text {HSC }}$, suddenly increased, indicating that the HSI had unstarted. Note that the pressure just upstream of the LSI cowl, PLSC, remained constant for this case, indicating that the HSI unstart did not unstart the LSI.

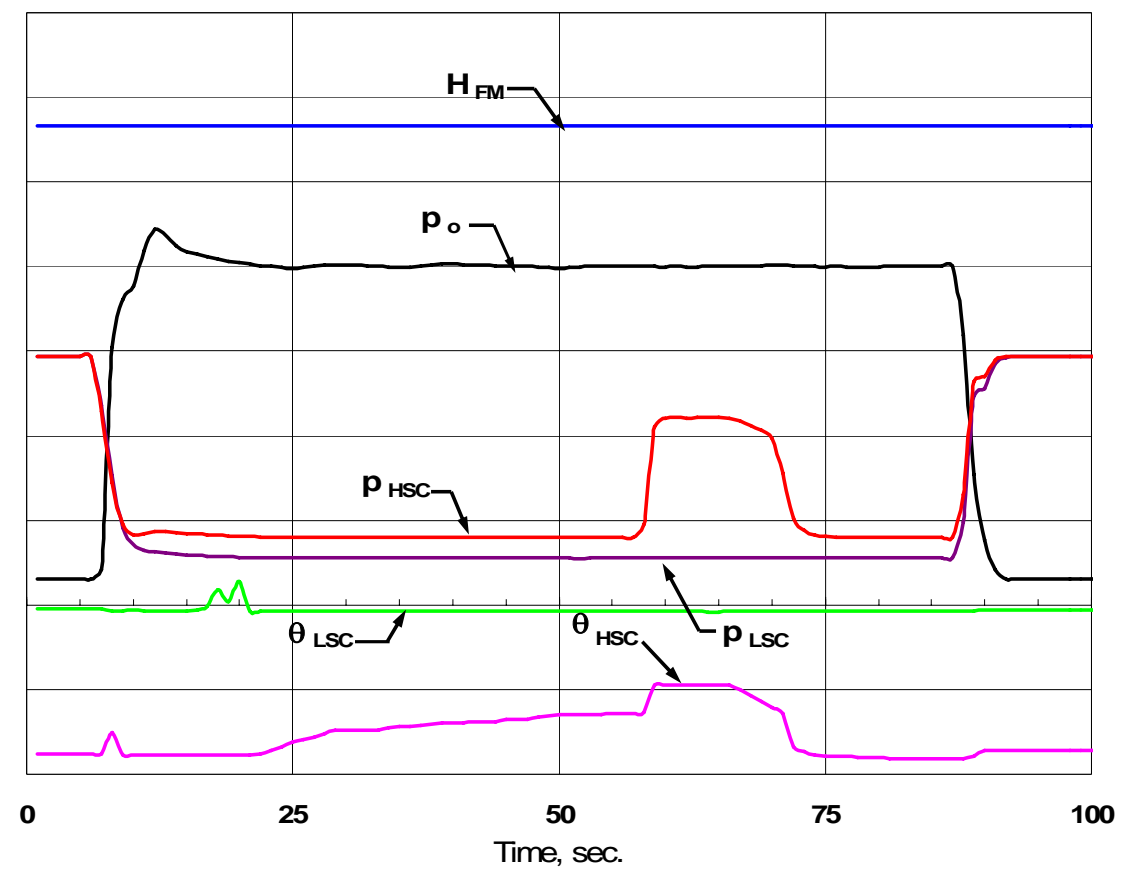

Figure 5. Variation of key parameters during a typical run $\left(\mathrm{H}_{\mathrm{HSI}, \mathrm{th}} / \mathrm{H}_{\text {design }}=0.60\right.$, boundary layer plate installed).

\section{Results and Discussion}

\section{A. Shock Wave Patterns}

Inviscid two-dimensional shock wave patterns corresponding to the LSC in the closed and fully opened positions are shown in Figs. 6(a) and 6(b), respectively, for the design HSI throat height and with the HSC set at $0^{\circ}$ relative to the freestream flow. These patterns were derived using standard oblique shock wave relationships. With the LSC closed (Fig. 6(a)), the LSC leading edge produces a shock well upstream of the HSC. When the LSC is opened, it produces a compression corner at the LSC hinge, the angle of which increases with increasing LSC open angle. The resulting shock wave pattern is shown in Fig. 6(b) with the LSC at the full open position. For this case, the shock produced at the LSC hinge impacted the HSC near the HSC kink. The competing effects of the LSC hinge shock and the LSI boundary-layer diversion on the HSI operability is evident in some of the test results to be presented.

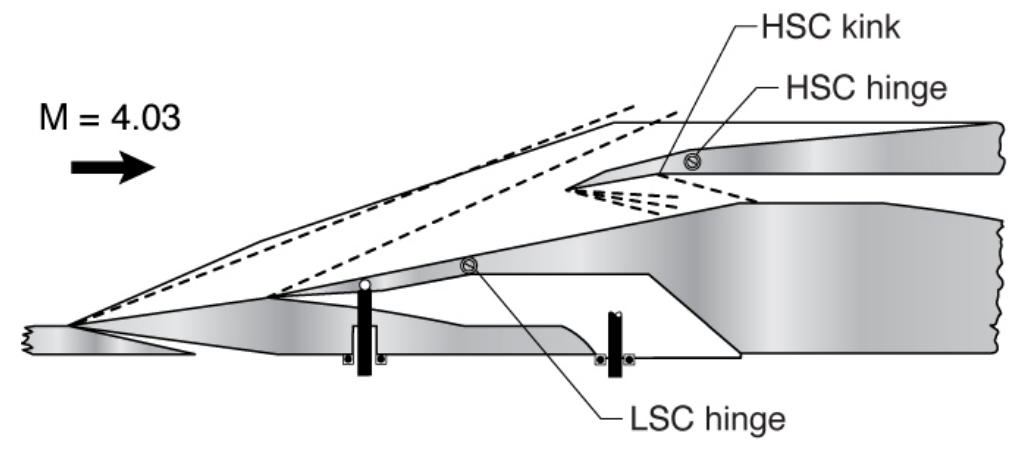

(a) LSC closed.

Figure 6. Inviscid, two-dimensional shock wave patterns $\left(\mathrm{H}_{\mathrm{HSI}}=\mathrm{H}_{\text {design }}\right)$. 


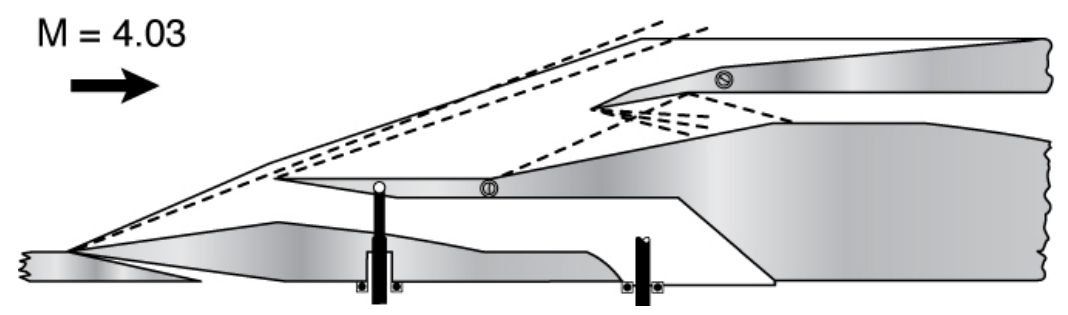

(b) LSC fully opened.

Figure 6. Concluded.

\section{B. High Speed Inlet Contraction Ratio Unstart}

Body centerline pressure distributions illustrating a typical HSI contraction-ratio induced unstart are shown in Fig. 7. These distributions correspond to a reduced HSI throat height of $60 \%$ of the design height, the LSC in the closed position $\left(\theta_{\mathrm{LSC}}=0^{\mathrm{O}}\right)$, and the flowmeter/back pressuring device set at minimum backpressure. During this test, the HSC rotation angle ( $\left.\theta_{\mathrm{HSC}}\right)$ was increased, increasing the HSI geometric internal contraction ratio ( $\left.\mathrm{CRI}_{\mathrm{HSI}}\right)$. Once $\mathrm{CRI}_{\mathrm{HSI}}$ was increased past a point, the pressure increased upstream of the HSI, as indicated by the pink pressure distribution corresponding to $\mathrm{t}=60 \mathrm{sec}$. This indicates that the flow was spilling upstream of the HSI and that the HSI had unstarted. Note that flow spillage from the HSI did not propagate upstream sufficiently to affect

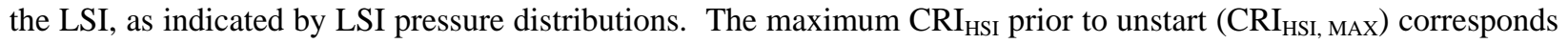
to the green pressure distribution ( $\mathrm{t}=57 \mathrm{sec}$.) in Fig. 7.

The LSI influence on HSI contraction ratio unstart performance is shown by the dark blue diamonds in Fig. 8. Here, $\mathrm{CRI}_{\mathrm{HSI}, \mathrm{MAX}}$ is plotted as a function of $\theta_{\mathrm{LSC}}$. When the LSC was opened to $17 \%$ of its full open position, the HSI could be operated at a higher contraction ratio prior to unstart. This effect was the result of the LSI diverting at least a portion of the low energy boundary layer away from the HSI.

\section{BODY CENTERLINE}

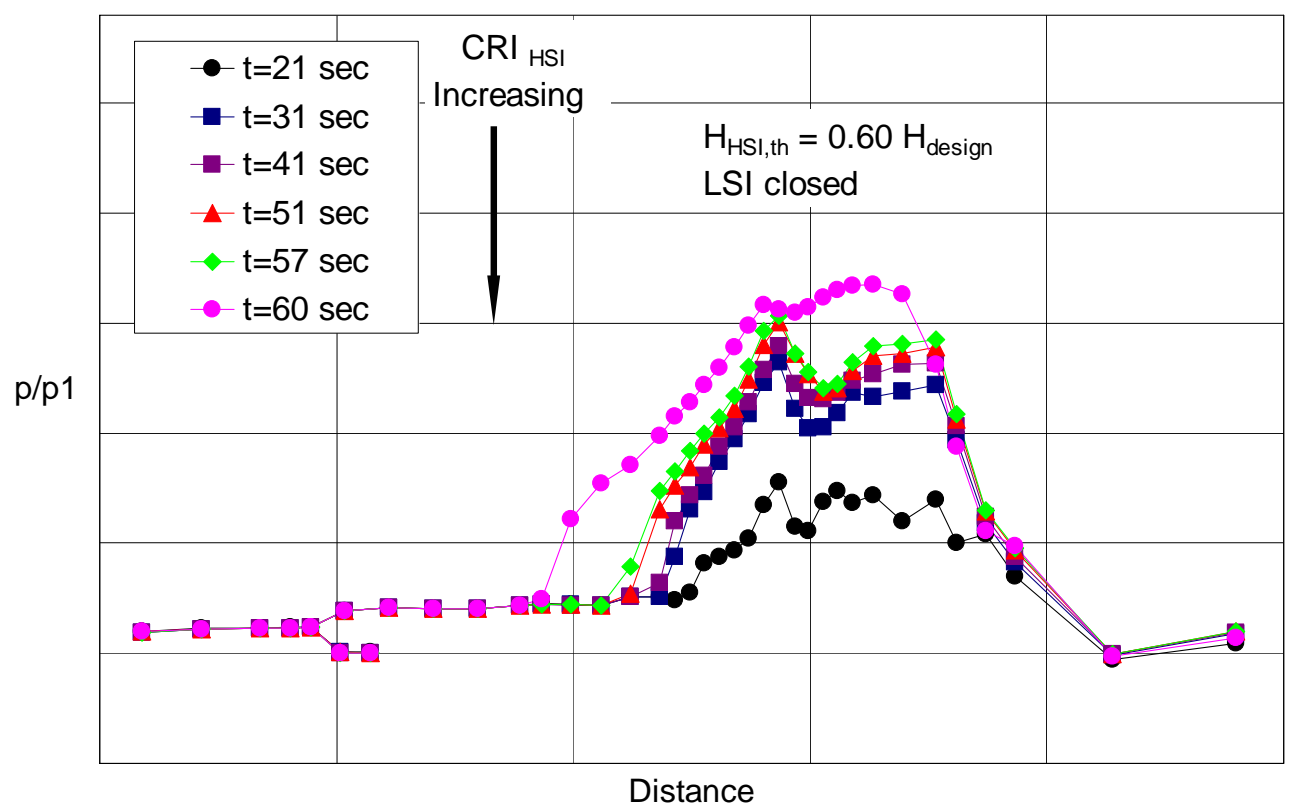

Figure 7. Typical body centerline wall static pressure distribution corresponding to a HSI contraction ratio unstart. $\left(\mathrm{H}_{\mathrm{HSI}}=0.60 \mathrm{H}_{\text {design, }}\right.$ BL plate installed, LSC closed $)$. 


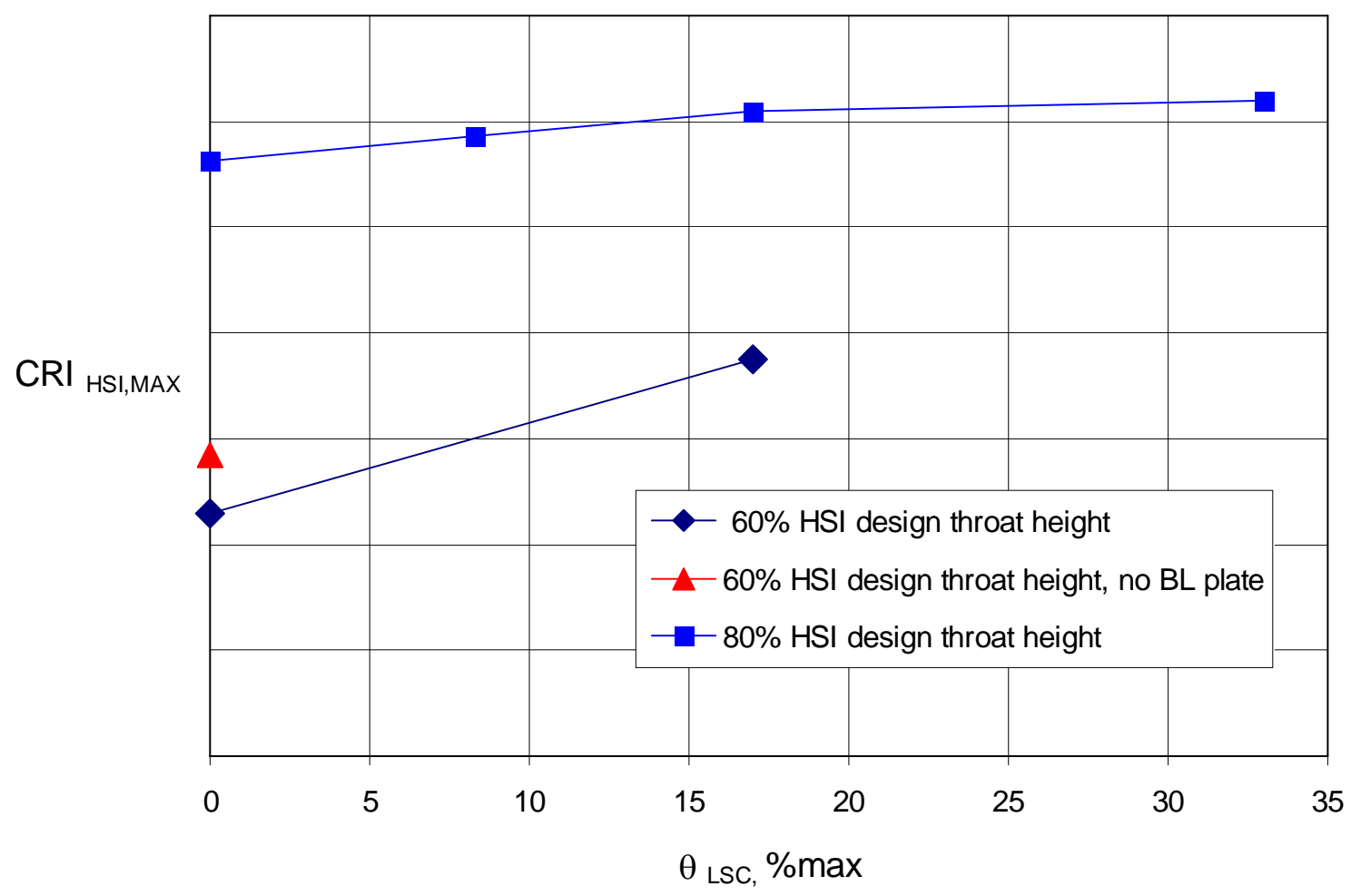

Figure 8. Effect of LSC open position on HSI contraction ration unstart limits.

The effect of boundary-layer thickness is also indicated in Fig. 8. As expected, a thinner boundary layer increased the contraction ratio unstart limit, due to lower flow energy loss. The contraction ratio unstart limit was also higher at the larger HSI throat height of $80 \%$ of design, because the HSI captured a larger percentage of flow outside of the boundary layer. The HSI could not be unstarted at its design throat height, even with the HSC at its full open position.

\section{High Speed Inlet Back-Pressure Induced Unstart}

Body centerline pressure distributions illustrating a typical HSI back-pressure induced unstart are shown in Fig. 9. These distributions correspond to a reduced HSI throat height of $60 \%$ of the design height and the LSC in the closed position. During this test, the height of the flowmeter/back pressure device was decreased, resulting in increasing back pressure to the HSI. Just before unstart ( $\mathrm{t}=160 \mathrm{sec}$.) the inlet reached its maximum permissible back pressure. As the flowmeter height continued to decrease ( $\mathrm{t}=162 \mathrm{sec}$.), the pressure increased upstream of the HSI, indicating that the HSI had unstarted. Note that flow spillage from the HSI did not propagate forward sufficiently to affect the LSI, as indicated by the LSI and forebody ramp pressure distributions. In fact, the LSI was not affected by a HSI unstart during any of the tests. 


\section{BODY CENTERLINE}

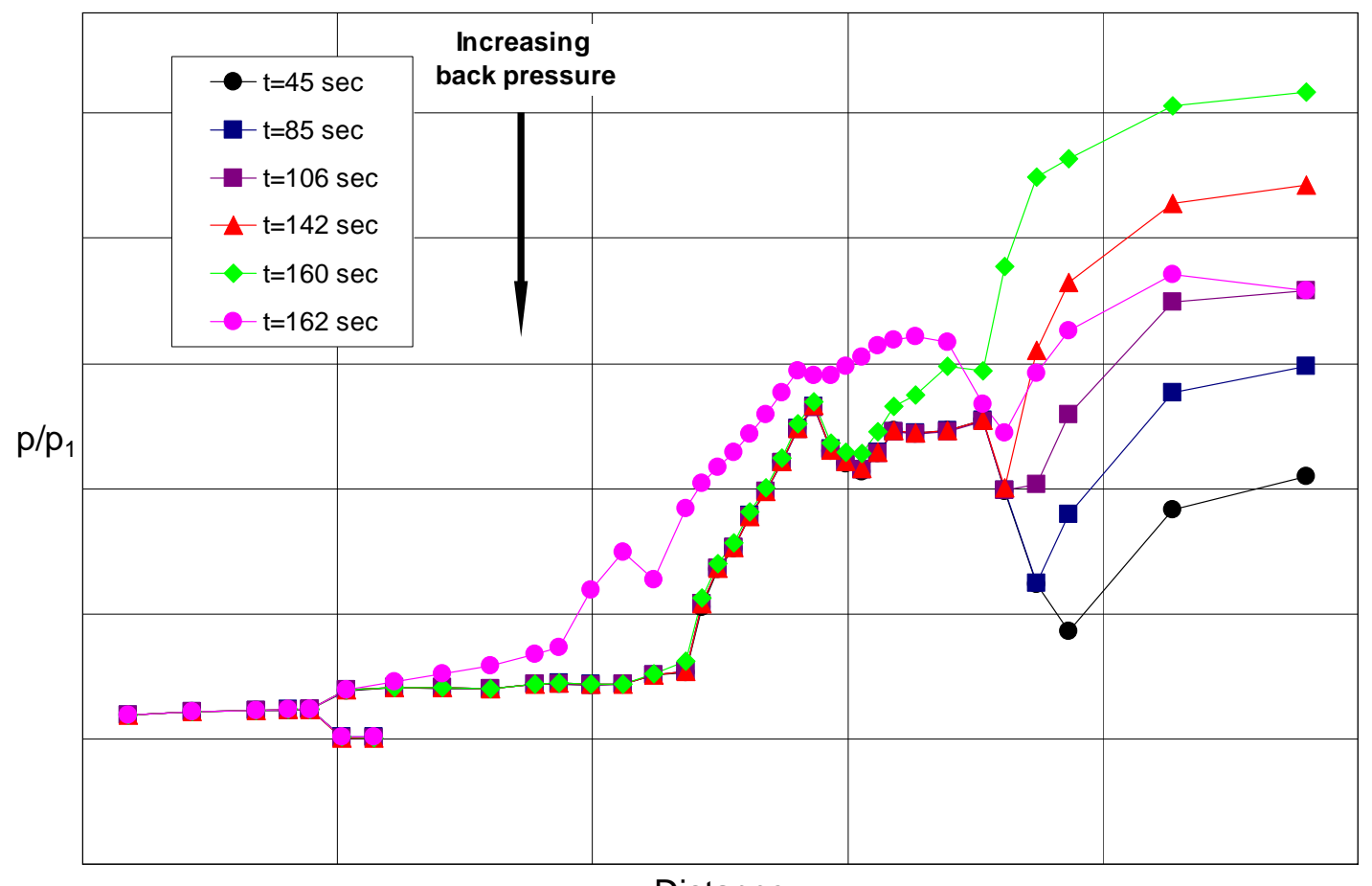

Distance

Figure 9. Body centerline wall static pressure distribution showing a HSI backpressure-induced unstart. $\left(\mathrm{H}_{\mathrm{HSI}}=0.60 \mathrm{H}_{\text {design }}\right.$, BL plate installed, LSC closed $)$.

The effect of the LSI on the HSI performance is shown in Fig. 10. Here the red line and symbols depict the same pressure distribution shown in Fig. 9, obtained at $t=160$ sec. just before the HSI unstarted. When the LSI was opened to $50 \%$ of its full open position, the HSI could be operated at significantly higher pressures prior to unstart. (Note that the HSI geometric contraction ratio is the same for both cases.) This effect was the result of the LSI diverting at least a portion of the low energy boundary layer away from the HSI. Additionally, increasing the LSC angle had the effect increasing the local Mach number upstream of the HSI. This would tend to improve the HSI operability, at least to the point where the LSC hinge shock (Fig. 6(b)) became an offsetting factor. Results obtained at the HSI design throat height and contraction ratio are shown in 11. Here, the beneficial effects of the LSI on HSI backpressure capability is less clear. One interesting observation is that when the LSC was in the full open position, the LSI would unstart, but did not cause the HSI to unstart, as shown by the red distribution in Fig. 11. The LSI would unstart at approximately $75 \%$ of its fully opened position regardless of HSI operation. 


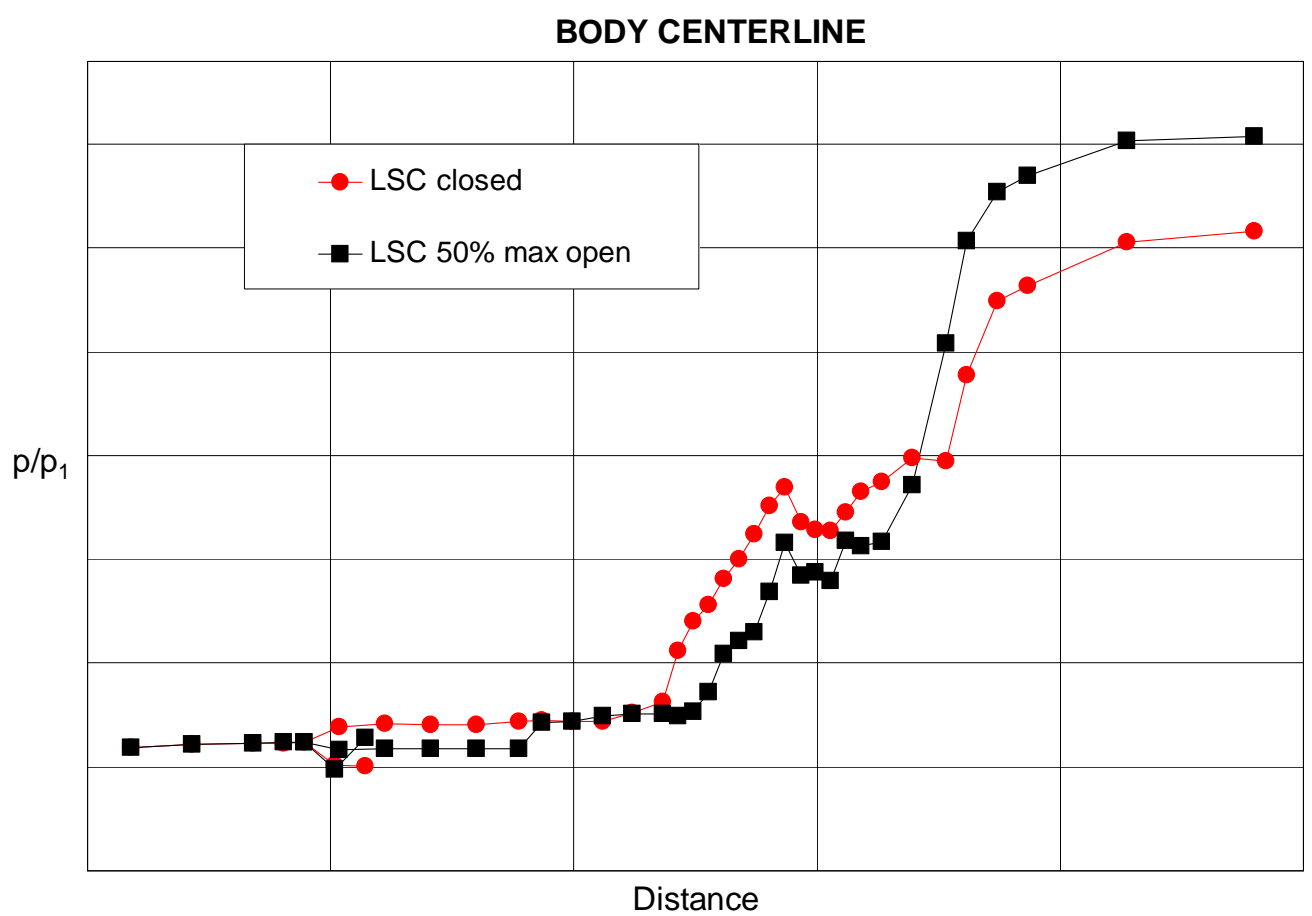

Figure 10. Body centerline pressure distribution showing effect of LSI cowl open angle on HSI backpressureinduced unstart limit. ( $\mathrm{H}_{\mathrm{HSI}}=0.60 \mathrm{H}_{\text {design, }}$, matched CRI ${ }_{\mathrm{HSI}}$, BL plate installed).

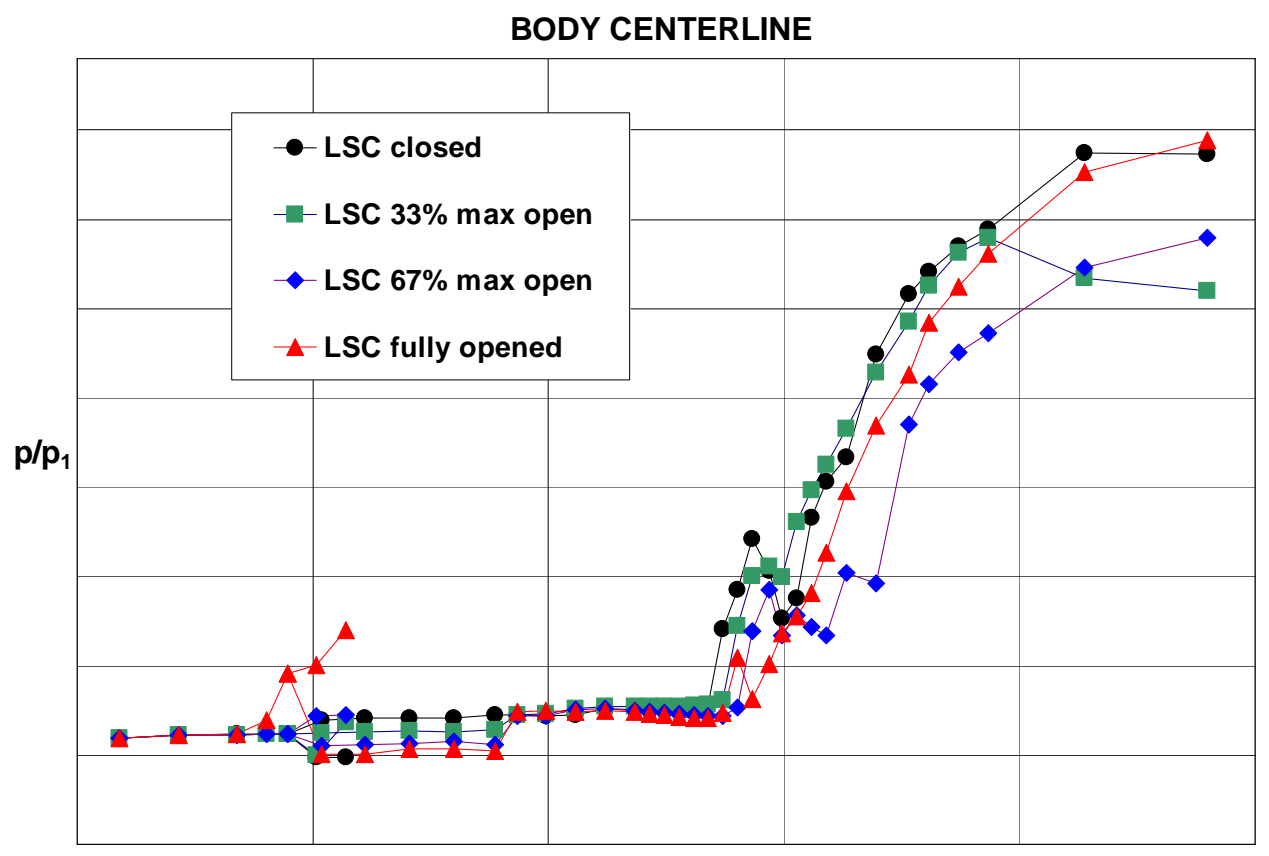

Distance

Figure 11. Body centerline pressure distribution showing effect of LSI cowl open angle on HSI backpressureinduced unstart limit. $\left(\mathrm{H}_{\mathrm{HSI}}=\mathrm{H}_{\text {design }}\right.$, $\mathrm{CRI}_{\mathrm{HSI}}=\mathrm{CRI}_{\text {design }}$, BL plate installed). 


\section{High Speed Inlet Performance Summary}

The inlet performance can be summarized in terms of the maximum pressure measured in the HSI as a function of geometric contraction ratio, as shown in Fig. 12(a) for the reduced HSI throat height of $60 \%$ of the design height. Note that as the LSC was opened, the HSI could be operated at higher pressures. This trend could also be observed when the HSI throat height was $80 \%$ of the design height, at least up LSC angles up to $33 \%$ the maximum (Fig. 12(b)). Increasing the LSC angle past this point tended to reduce the maximum HSI pressure obtainable prior to unstart. This is most likely due to the effect of the secondary shock created at the joint of the LSI flap when the LSI was opened, as shown in the shock wave patterns in Figs. 6(a) and 6(b). At the design HSI throat height (Fig. 12(c)), there was no significant performance benefit gained by opening the LSC. This trend is also indicated in the pressure distributions shown in Fig. 11.

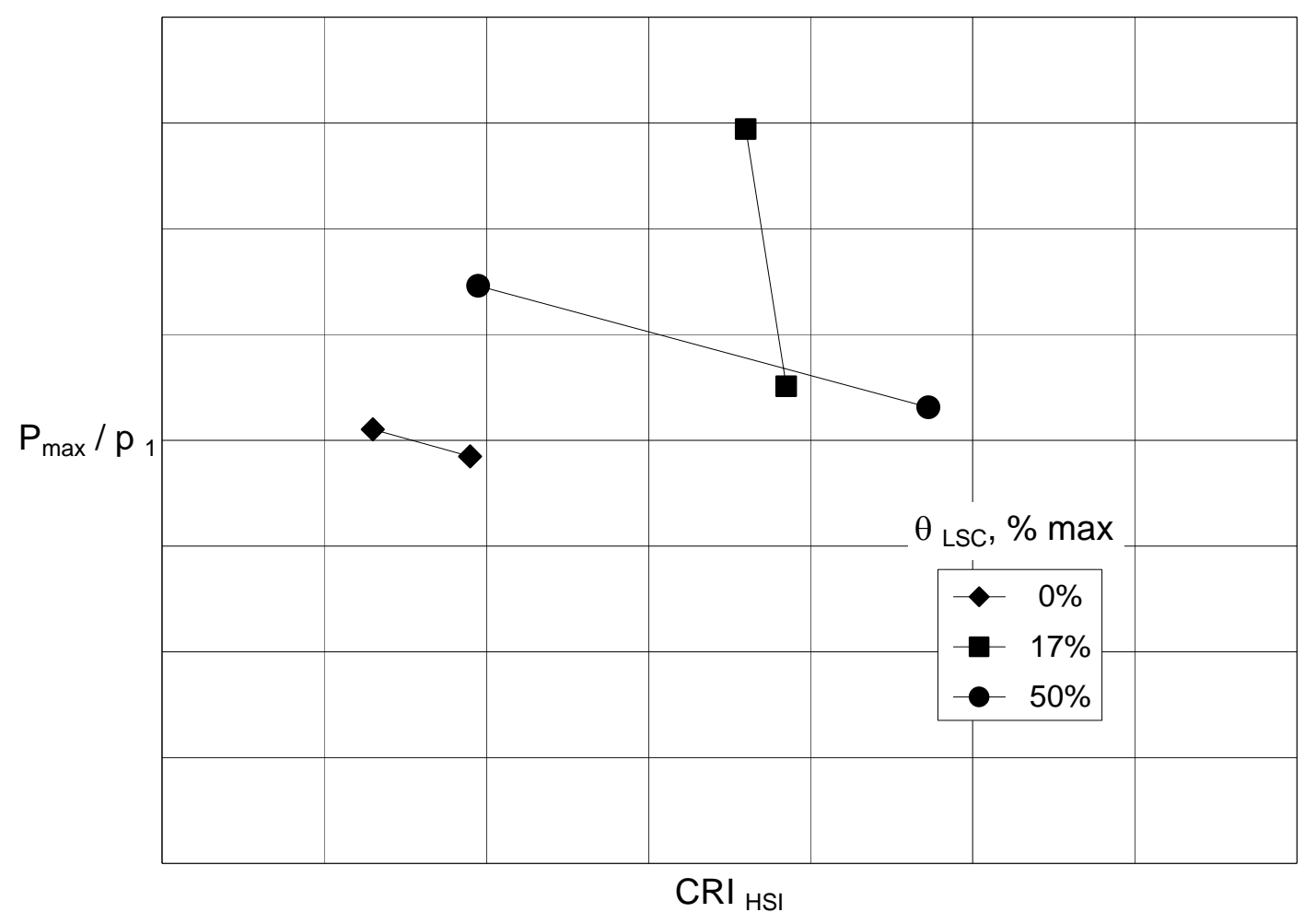

(a) $\mathrm{H}_{\mathrm{HSI}}=0.60 \mathrm{H}_{\text {design }}$.

Figure 12. Maximum HSI pressure as a function of CRI $\mathrm{HSI}_{\text {and }}$ LSC position. 


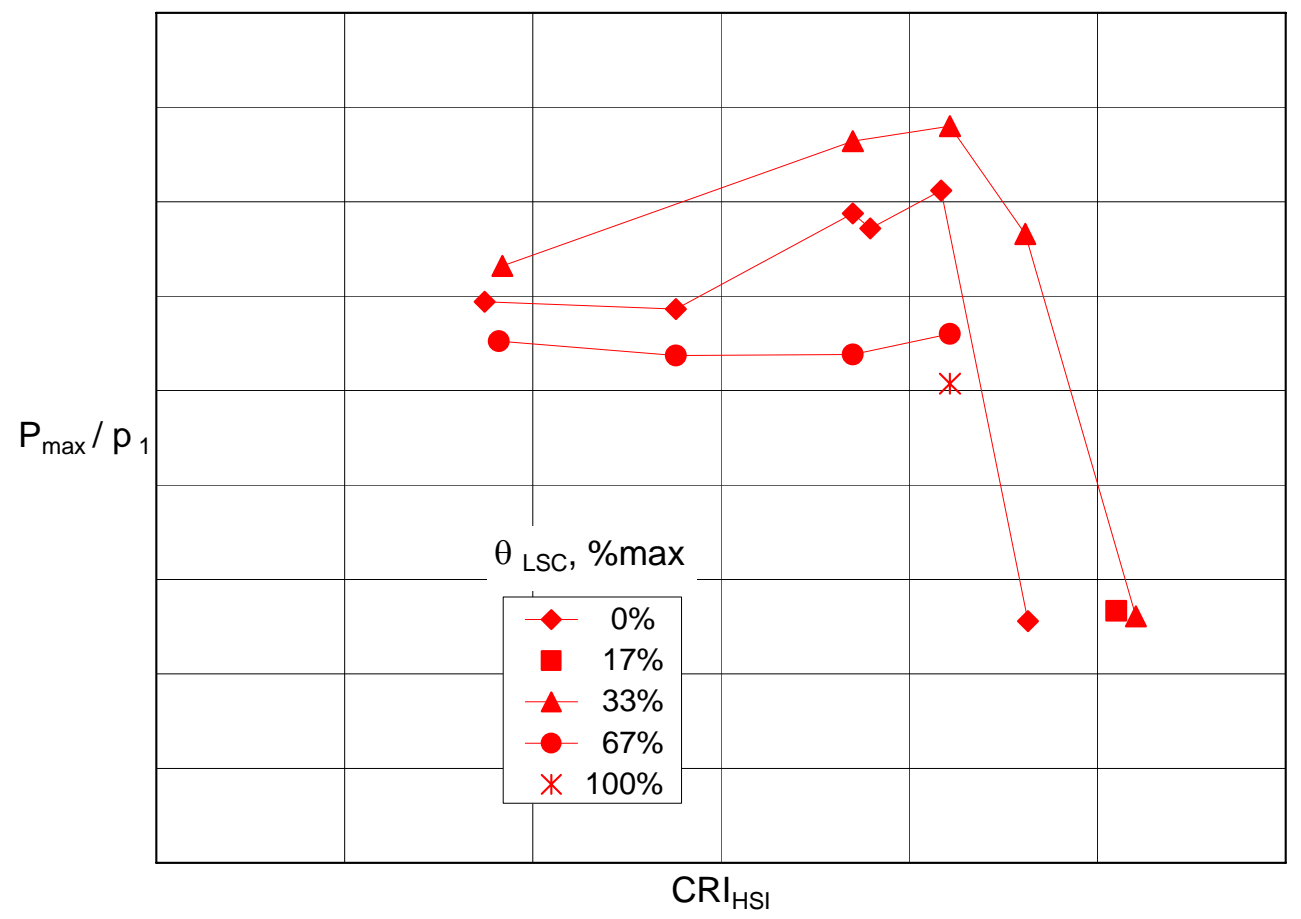

(b) $\mathrm{H}_{\mathrm{HSI}}=0.80 \mathrm{H}_{\text {design }}$.

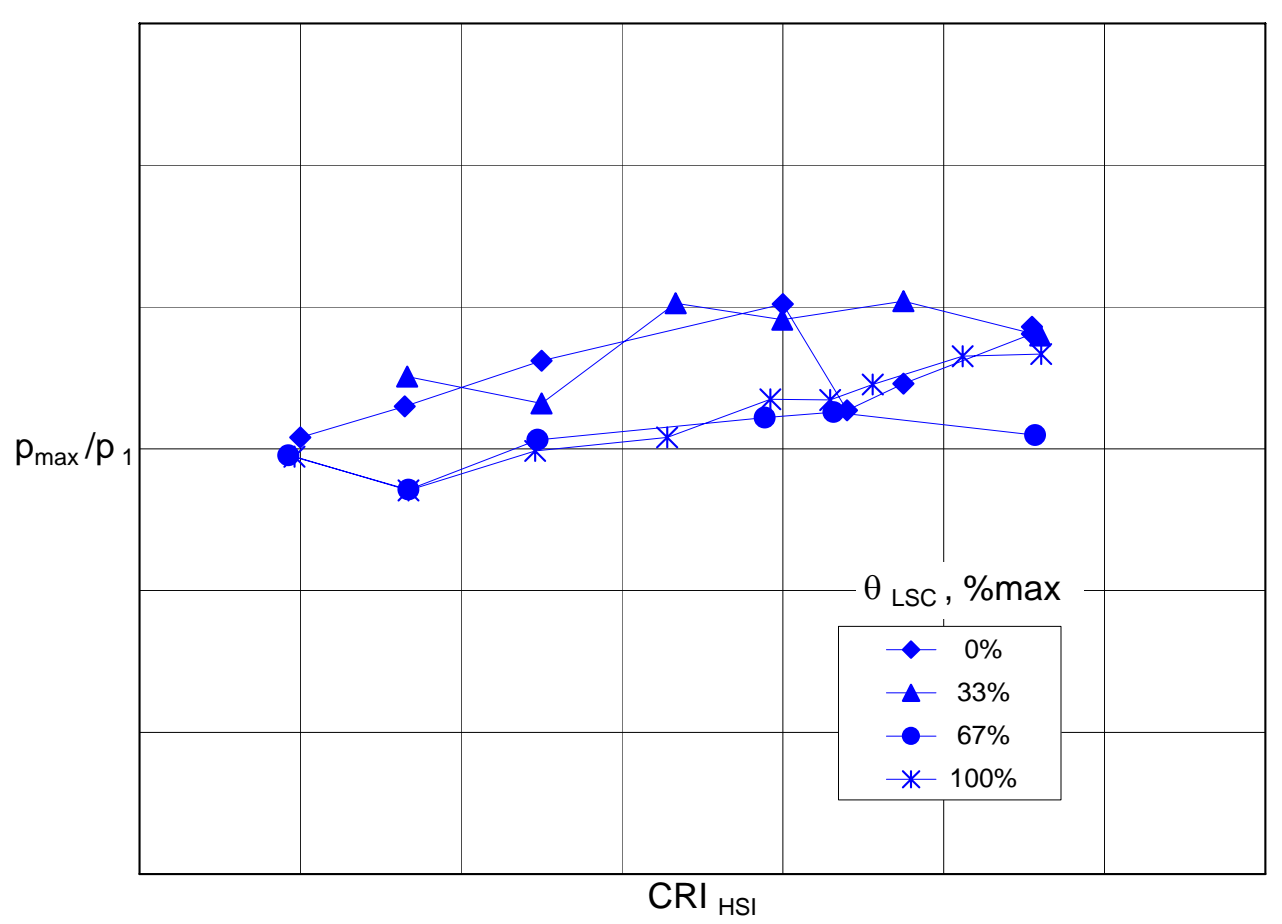

(c) $\mathrm{H}_{\mathrm{HSI}}=\mathrm{H}_{\text {design }}$.

Figure 12. Concluded. 
The results for all three HSI throat heights are shown in Fig. 13. Note that the best performance in terms of $\mathrm{p}_{\max } / \mathrm{p}_{1}$ was obtained with the HSI throat set at $80 \%$ of the design height and with the LSC set at $33 \%$ of its full open position.

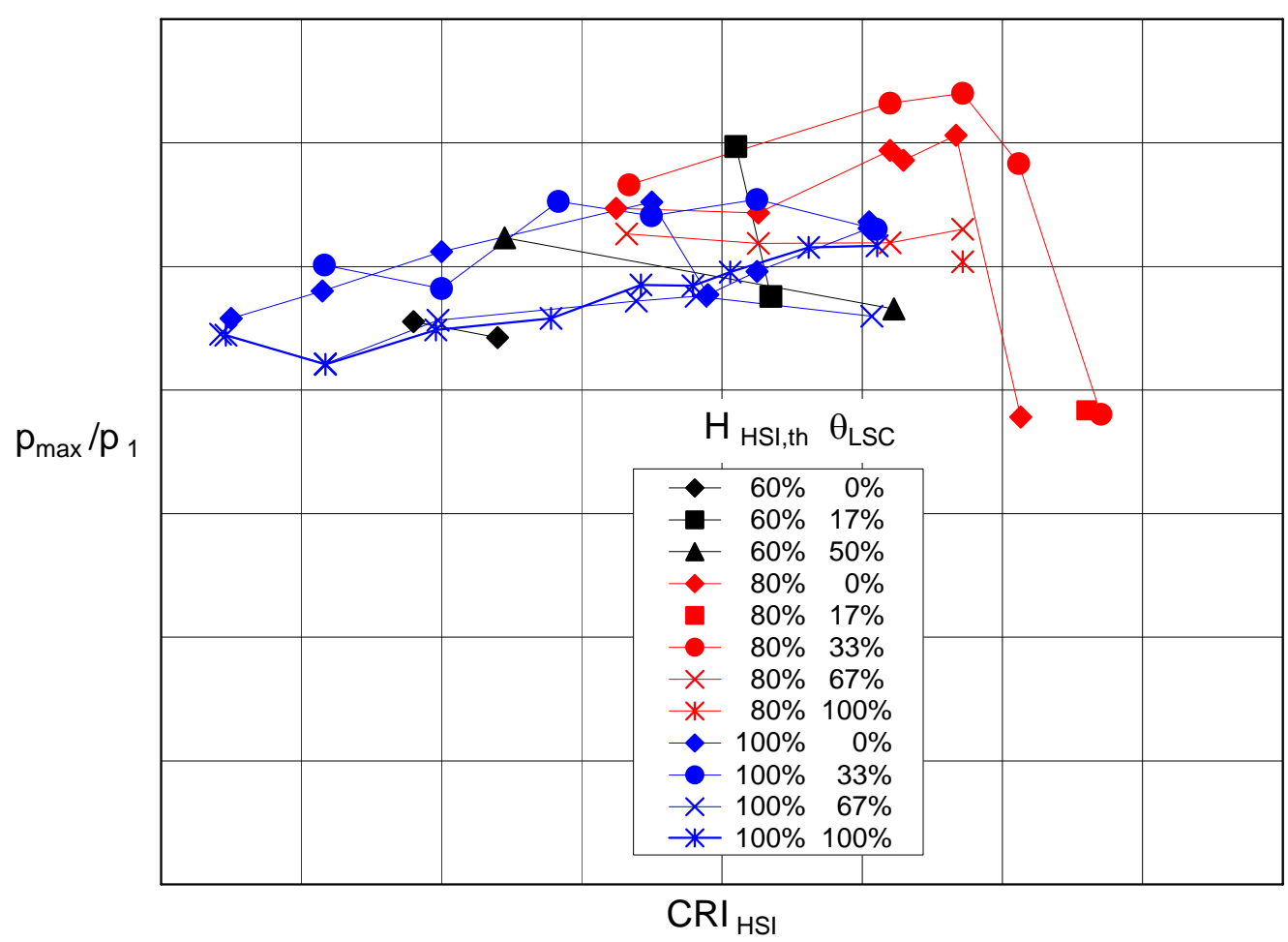

Figure 13. HSI performance summary

\section{Concluding Remarks}

An experimental study was conducted to evaluate the performance of a turbine based combined cycle (TBCC) inlet concept, consisting of a low speed turbojet inlet and high speed dual-mode scramjet inlet. The main objectives of the study were (1) to identify any interactions between the low and the high speed inlets during the mode transition phase in which both inlets are operating simultaneously and (2) to determine the effect of the low speed inlet operation on the performance of the high speed inlet. Tests were conducted at a nominal freestream Mach number of 4 using an 8 percent scale model representing a single module of a TBCC inlet. A flat plate was installed upstream of the model to produce a turbulent boundary layer which simulated the full-scale vehicle forebody boundary layer. A flowmeter/back pressure device, with remote actuation, was attached aft of the high speed inlet isolator to simulate the back pressure resulting from dual-mode scramjet combustion. Results indicate that the inlets did not interact with each other sufficiently to affect inlet operability. Flow spillage resulting from a high speed inlet unstart did not propagate far enough upstream to affect the low speed inlet. Also, when the LSC was opened more than $75 \%$ of its full open position, the LSI would unstart, but did not cause the HSI to unstart.

The net result of the dual flowpath system is that the LSI was beneficial to the operability of the HSI for HSI throat heights of $60 \%$ and $80 \%$ of the original design height. This was due to the removal of the boundary layer which outweighed the effect of the secondary shock created at the joint of the LSC flap when the LSC was opened to certain positions. The Mach number ahead of the HSI also increased, as the LSC was opened, which tended to increase the contraction ratio limit of the HSI. At the design HSI throat 
height, the boundary layer was a smaller percentage of the inlet height, resulting in negligible overall benefit. Overall, the best performance in terms of maximum back pressure was obtained with the HSI throat set at $80 \%$ of the design height and with the LSC set at 33\% of its full open position.

\section{Acknowledgments}

The authors would like to thank Mr. Lloyd Wilson for preparing the model for testing and operating the M4BDF. The authors would also like to thank Mr. Roger Jones for preparing the vehicle and model figures used in this report.

\section{References}

${ }^{1}$ Snyder, L. E., Escher, D. W., DeFrancesco, R. L., Gutierrez, J. L., and Buckwalter, D. L., “Turbine Based Combination Cycle (TBCC) Propulsion Subsystem Integration," $40^{\text {th }}$ AIAA/ASME/SAE/ASEE Joint Propulsion Conference and Exhibit, July 11-14, 2004, Fort Lauderdale, Florida, AIAA 2004-3649.

${ }^{2}$ Marshall, A. W., Gupta, A. K., Lewis, M. J., and Lavelle, T., "Critical Issues in TBCC Modeling," $40^{\text {th }}$ AIAA/ASME/SAE/ASEE Joint Propulsion Conference and Exhibit, July 11-14, 2004, Fort Lauderdale, Florida, AIAA 2004-3827.

${ }^{3}$ Clough, J. A. and Lewis, M. J., "Comparison of Turbine-Based Combined-Cycle Engine Flowpaths," $12^{\text {th }}$ AIAA International Space Planes and Hypersonic Systems and Technologies Conference, December 15-19, 2003, Norfolk, Virginia, AIAA 2003-6932.

${ }^{4}$ Moses, P. L., Rausch, V. L., Nguyen, L. T. and Hill, J. R., "NASA Hypersonic Flight Demonstrators - Overview, Status, and Future Plans,” Acta Astronautica [online journal], Vol. 55 (2004), pp. 619-630, URL: http://www.sciencedirect.com.

${ }^{5}$ Rodi, P. E., Emami, S., and Trexler, C. A., "Unsteady Pressure Behavior in a Ramjet/Scramjet Inlet," Journal of Propulsion and Power, Vol. 12, No. 3, May - June 1996, pp. 486-493.

${ }^{6}$ Labview, Data Acquisition Software Package, National Instruments, Austin TX, URL: http://www.ni.com/labview/.

${ }^{7}$ Trexler, C. A., and Smart, M, K., "Test and Evaluation of X-43C Inlet Designs at a Simulated Mach 5 Flight Condition,” 2003 Joint JANNAF CS/APS/PSHS/MSS Meeting, Colorado Springs, Colorado, December 1-5, 2003.

${ }^{8}$ Lau, K. Y., and Vaporean, C. N., "Parametric Boundary Layer Transition Study for NASP-Like Configurations Using Linear Stability Analyses,” NASP Mid-Term Technology Review, Paper 283, Monterey, CA, April 1992. 